\title{
CLINICAL ANALYSIS OF PATIENTS WITH LOW BACK PAIN IN THE EMERGENCY DEPARTMENT
}

\author{
ANÁLISE CLÍNICA DE PACIENTES COM DOR LOMBAR NO DEPARTAMENTO \\ DE EMERGÊNCIA
}

\section{ANÁLISIS CLÍNICO DE PACIENTES CON DOLOR LUMBAR EN EL DEPARTAMENTO DE EMERGENCIA}

Ruy da Silva Rodrigues, ${ }^{1}$ Eduardo Bastos de Siouelra, ${ }^{1}$ Leandro Gomes Brito, ${ }^{1}$ Rudy Lenk Fagundes, ${ }^{1}$ Caio Tannus Vianna Ribeiro ${ }^{2}$

1. Hospital Estadual Dr. Jayme Santos Neves, Department of Neurosurgery, Serra, ES, Brazil.

2. Hospital do Trabalhador, Department of Neurosurgery, Curitiba, PR, Brazil.

\begin{abstract}
Objective: To describe the daily practice in an emergency service and to provide relevant data for future studies about the treatment of low back pain from the perspective of emergency medicine. Methods: Analysis of hospital records and review of medical records. Results: 2,434 patients were attended between January 1 and December 31, 2017 with the complaint of low back pain. Radiographs of the spine were performed in $15.7 \%$ of patients and computerized tomography scans in $7.6 \%$. Eighty-five patients required hospitalization, with a mean hospital stay of 8.3 days. The rate of use was $52.7 \%$ for tricyclic or antiepileptic drugs and $12 \%$ for strong opioids among hospitalized patients. Conclusions: A high prevalence of low back complaints was observed in the emergency care service (4.6\% of total emergency room visits during the year), with low hospitalization potential. The rates of hospitalization and tomographic examinations were higher than those observed in similar studies, with a lower proportion of radiograph and strong opioid use as compared with the same studies. The paucity of national and international data for more in-depth comparisons makes clear the need for further studies and development of new recommendations specifically targeting this subset of patients. Level of evidence IV; Prognostic studies.
\end{abstract}

Keywords: Low Back Pain; Emergency Medicine; Drug Therapy.

RESUMO

Objetivo: Descrever a prática diária em um serviço de pronto atendimento e produzir dados relevantes para estudos futuros relacionados com tratamento da dor lombar na perspectiva da medicina de emergência. Métodos: Análise dos registros hospitalares e revisão de prontuários. Resultados: Foram realizados 2.434 atendimentos entre $1^{\circ}$ de janeiro e 31 de dezembro de 2017 com a queixa de dor lombar. Foram realizadas radiografias da coluna em 15,7\% dos pacientes e tomografias computadorizadas em 7,6\%. Oitenta e cinco pacientes precisaram de internação hospitalar, com tempo médio de internação de 8,3 dias. A taxa de utilização de antidepressivos tricíclicos ou antiepilépticos foi de $52,7 \%$ para os pacientes internados e a de opioides fortes foi de $12 \%$. Conclusões: Observou-se uma alta taxa de prevalência de queixa de dor lombar no serviço de pronto atendimento (4,6\% do total de atendimentos do pronto-socorro durante o ano), com baixo potencial de internação. A taxa de internação e realização de exames tomográficos foi maior que a observada em estudos semelhantes, com uma menor proporção de uso de radiografias e opioides fortes em comparação com os mesmos estudos. A escassez de dados nacionais e internacionais para comparações mais profundas torna clara a necessidade de estudos adicionais e desenvolvimento de novas recomendações, visando especificamente esse subgrupo de pacientes. Nível de evidência IV; Estudos prognósticos.

Descritores: Dor Lombar; Medicina de Emergência; Tratamento Farmacológico.

\section{RESUMEN}

Objetivo: Describir la práctica diaria en un servicio de atención rápida y producir datos relevantes para estudios futuros relacionados con tratamiento del dolor lumbar en la perspectiva de la medicina de emergencia. Métodos: Análisis de los registros hospitalarios y revisión de historiales. Resultados: Se realizaron 2.434 atendimientos entre el 1 de enero y el 31 de diciembre de 2017 con la queja de dolor lumbar. Fueron realizadas radiografías de la columna en el 15,7\% de los pacientes y tomografías computarizadas en el 7,6\%. Ochenta y cinco pacientes precisaron internación hospitalaria, con tiempo promedio de internación de 8,3 días. La tasa de uso de antidepresivos tricíclicos o antiepilépticos fue del 52,7\% para los pacientes internados y la de opioides fuertes fue del 12\%. Conclusiones: Se observó una alta tasa de prevalencia de queja de dolor lumbar en el servicio de atención rápida (4,6\% del total de atenciones de primeros auxilios durante el año), con bajo potencial de internación. La tasa de internación y realización de exámenes tomográficos fue mayor que la observada en estudios semejantes, con una menor proporción de uso de radiografías y opioides fuertes en comparación con los mismos estudios. La escasez de datos nacionales e internacionales para comparaciones más profundas hace clara la necesidad de estudios adicionales y el desarrollo de nuevas recomendaciones, dirigidas específicamente a este subgrupo de pacientes. Nivel de evidencia IV; Estudios pronósticos.

Descriptores: Dolor de la Región Lumbar; Medicina de Emergencia; Quimioterapia.

Study conducted at the Hospital Estadual Dr. Jayme Santos Neves. Av. Paulo Pereira Gomes, sem número, bairro Morada de Laranjeiras, Serra, ES. Brazil Correspondence: Ruy da Silva Rodrigues. Rua Lucio Bacelar, 167, Apto 802, Praia da Costa, Vila Velha, ES. 29101-030. ruyrodriguesnc@gmail.com 


\section{INTRODUCTION}

Various painful syndromes, including multiple presentations of pain in the spinal region (acute lumbar pain, chronic pain, acute chronic pain, radiating and referred pain, back pain, and pains in the hips), are some of the main complaints in emergency care services around the world, corresponding to $4.38 \%$ of consultations in these services. ${ }^{1}$ In recent years, the approach to this symptom from the emergency medicine perspective has been gaining more academic interest with the publication of several articles describing the epidemiology and the clinical course of this complaint. We have observed growing concern related to reducing the impact on emergency services, since, in general, we see this condition as an infirmity with a low potential for complications but that may involve high treatment costs.

About $90 \%$ of cases are diagnosed as non-specific low back pain and the principles of emergency treatment are to identify the warning signs for serious disease, quickly relieve the symptoms, and provide information on the benign nature and self-limitation of the disease. The probability of chronification varies according to the population studied and the definition used, and the risks described vary from 19 to $35 \%, 2,3$ which ends up creating a secondary demand that later also encounters healthcare and outpatient clinic difficulties. The high prevalence of this type of disease progression, associated with a primary care system with numerous deficiencies, seems to contribute to the cycle of inefficiency in the health system. This cycle, in turn, is perpetuated by favoring multiple undesirable and potentially avoidable return visits to emergency services, which denotes the poor utilization of healthcare system resources and leads to the overcrowding of these facilities.

Management of these patients continues to present a wide range of clinical practices, despite the various publications and disclosures of guidelines for the treatment of acute low back pain., ${ }^{4,5}$ Different rehabilitation modalities and physical therapies with little or no level of evidence are often used. ${ }^{6,7}$ We observed that the topic is still treated with disinterest in and ignorance of the medical field among several specialties, which may favor the excessive use of medications and the execution of unnecessary imaging examinations, actions that end up increasing treatment costs without offering better results. ${ }^{8,9}$

This study aims to call attention to the daily care routine for patients with acute lumbar pain in a large emergency care service, to describe common practices, and to evaluate them according to the most relevant evidence available in the current literature. In this way, we will reinforce the need for further studies focused on answering the questions related to better workflow for the care of these patients in these services.

\section{METHODS}

This study was approved by the local Institutional Review Board (CEP 4.127.503) and exempted from use of the Informed Consent Form because it is a retrospective analysis of the hospital database and medical records (case series). A systematized search was conducted of the patients whose first consultation was performed by the neurosurgical team of the Hospital Estadual Dr. Jayme Santos Neves, located in the city of Serra, in Espírito Santo. Patients with lumbar pain were classified through diagnosis using the International Statistical Classification of Diseases and Related Health Problems (ICD-10) at the time of discharge (ICDs M51.1, M54.3, M54.4, M54.5). The selection of these codes was made following an assessment of those most often used for patients with acute low back pain or acute chronic conditions, with or without its radiation to the lower limbs, without taking the presence of warning signs or the history of mild traumas into account. Thus, it did not include all of the patients with complaints of lumbar pain, since during the search the use of less specific codes, such as acute pain (R52.0) and other chronic pain (R52.2), was also identified. Nor was it concerned with strict anatomical definitions, for which we are recommending the future adoption of a prospective model focused on the use of a single terminology, in accordance with what has been proposed by other researchers.
Data such as sex, age, medication administered, imaging examinations performed, and the need for and duration of hospitalization were collected.

The hospital data were loaded into a table and the results presented as means, absolute values, and percentages. To calculate the profile of medications administered, a sample collection was performed using a randomization tool aimed at maintaining the characteristics of the original sample. For the cost calculations, the 2017 SIGTAP table was used as a basis, without taking the medication purchasing costs into account. (Table 1)

The Hospital Estadual Dr. Jayme Santos Neves is located in the city of Serra, in the Greater Vitória metropolitan area and considered one of the largest emergency and urgent care hospitals in the state of Espírito Santo. It has 427 beds, 44 of which are for intensive care. Initial treatment of patients who arrive by their own means is conducted according to an adaptation of the workflows proposed by the Manchester protocol, which sends screened patients with complaints of low back pain and a classification of white, blue, green, or yellow directly to the neurosurgery team. Orange screening, which corresponds to intense pain, indicates a referral to another specialty (medical clinic) for immediate attention and was not the subject of this study because of the very small number of these patients (only 55 in 12 months), with a high proportion of renal colicky-type pain (46 patients). The emergency care profile includes only adult patients (over 18 years of age).

\section{RESULTS}

During 2017, 52,886 urgent and emergency care consultations were conducted. Of these, 2,434 visits (4.6\%) were recorded as the ICDs most frequently used for low back pain complaints. (Table 2) There were 2,058 patients who had between 1 and 10 consultations during the year. Visits by month and by day of the week were heterogeneously distributed over the year with a higher proportion of cases attended during health center working hours $(60 \%$ of cases attended Monday through Friday, from 7:00 am to 5:00 pm), with a higher concentration at the beginning of the week. (Figure 1) According to the screening criteria adopted by the hospital, $71.4 \%$ were classified as yellow (urgent) and $27.6 \%$ as green (not urgent). The percentage of female patients was $51.4 \%$ and the mean age was 45.8 years. (Table 3) Among the patients attended, 8.5\% underwent another emergency consultation for the same complaint within 30 days. Two hundred and seventy-eight (278) patients had multiple consultations during the year. (Figure 2) Lumbosacral spinal radiographs were used in $15.7 \%$ of the visits and computed tomography of the same region was used in $7.6 \%$. Predominant use of the ICD for low back pain was observed, with a smaller proportion of the complaints classified as radiating pain. Among the hospitalized patients, there was a change in this ratio, with a predominance of patients with radiating pain. (Figure 3 ) The percentage of patients with a stay of more than 24 hours was $8.6 \%$ and $3.5 \%$ of the total number of

Table 1. Costs.

\begin{tabular}{c|c}
\hline Medical care & $\mathrm{R} \$ 26,686$ \\
\hline Drug administration care & $\mathrm{R} \$ 1,346$ \\
\hline Radiographies & $\mathrm{R} \$ 4,306$ \\
\hline Computed tomography computadorizadas & $\mathrm{R} \$ 18,704$ \\
\hline Complete hemogram & $\mathrm{R} \$ 333$ \\
\hline Urinalysis & $\mathrm{R} \$ 207$ \\
\hline Total & $\mathrm{R} \$ 51,704$ \\
\hline
\end{tabular}

Medication costs not included.

Table 2. ICDs analyzed

\begin{tabular}{c|c}
\hline M51.1 & Disorders of lumbar discs and other discs with radiculopathy \\
\hline M54.3 & Sciatica \\
\hline M54.4 & Lumbago with sciatica \\
\hline M54.5 & Low back pain \\
\hline
\end{tabular}


patients required hospitalization for an average period of 8.3 days. The rates of strong opioid and corticosteroid use in the emergency room were $9.8 \%$ and $21.3 \%$, respectively, (Figure 4 ) while the same rates were $12 \%$ and $2.7 \%$ in hospitalizations. The rate of neuropathic pain medication use (tricyclic antidepressants or antiepileptics) in hospitalizations was $52.7 \%$. (Figure 5)

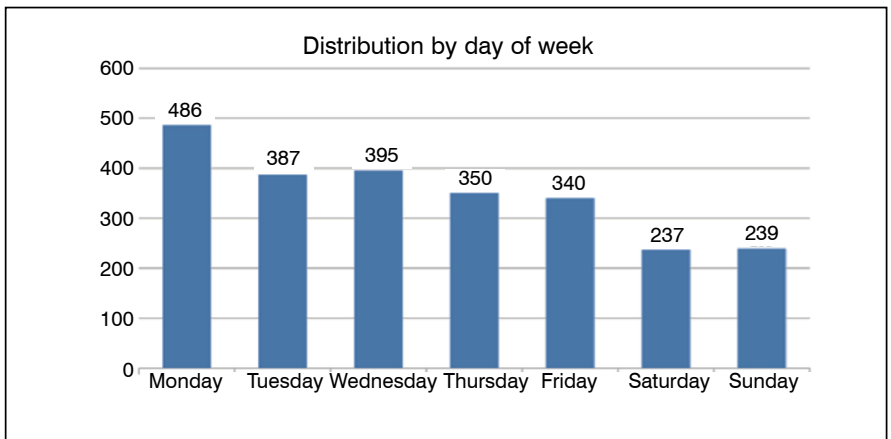

Figure 1. Distribution by day of week.

Table 3. Epidemiology and resource utilization.

\begin{tabular}{c|c}
\hline Consultations (n) & 2434 \\
\hline Female sex (\%) & 51.4 \\
\hline Mean age (years) & 45.8 \\
\hline IV medication (\%) & 87.7 \\
\hline Radiographs (\%) & 15.7 \\
\hline Tomography (\%) & 7.6 \\
\hline Hemogram (\%) & 13.6 \\
\hline Urinalysis (\%) & 2.3 \\
\hline Length of stay > 24h (\%) & 8.6 \\
\hline Hospitalization (\%) & 3.5 \\
\hline
\end{tabular}

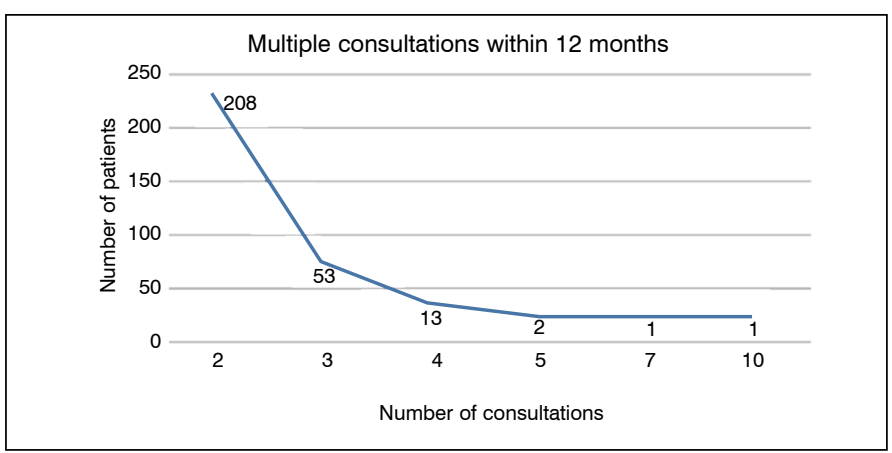

Figure 2. Multiple consultations within 12 months.

\section{DISCUSSION}

While the recommendations are similar in the guidelines of various countries, the low back pain care and management workflows appear to be greatly influenced by culture, with differences related to the professional responsible for emergency care and outpatient follow-up (general practitioners, orthopedists, neurosurgeons, or rheumatologists) and to the amount of resources available for treatment. In our environment, underutilization of primary care mechanisms is common, with super-utilization of specialized outpatient clinics and emergency services, even during health center operating hours. Although no direct comparisons between the treatments performed by different specialties exist, it is interesting to note that in recent years some developed countries have adopted national strategies to encourage the pain management in less complex environments, aimed at cost reduction and without apparent damage to clinical outcomes. Acute low back pain is a frequent complaint in developing countries, with a tendency towards increasing frequency in the years to come, ${ }^{10-12}$ and a portion of the costs of emergency

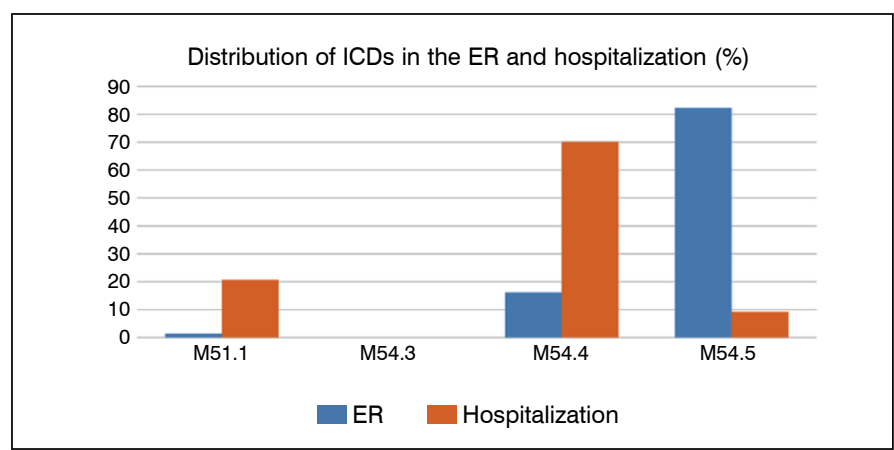

Figure 3. Distribution of ICDs in the ER and during hospitalization.

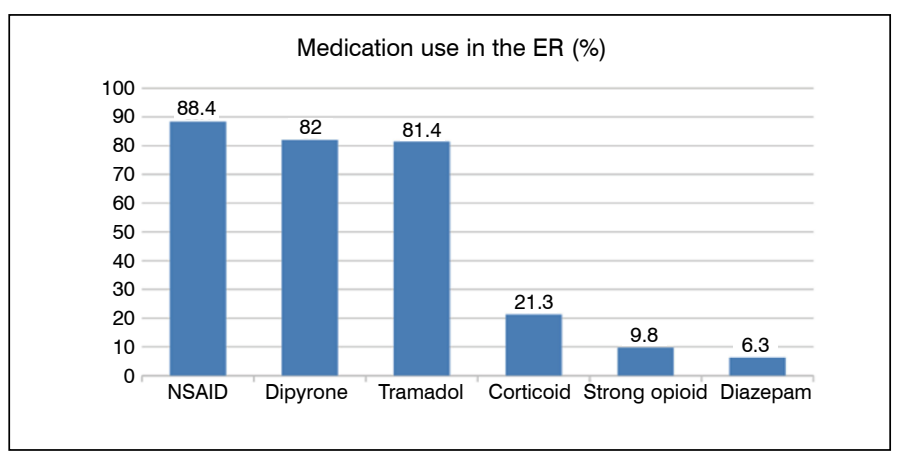

Figure 4. Medication use in the ER.

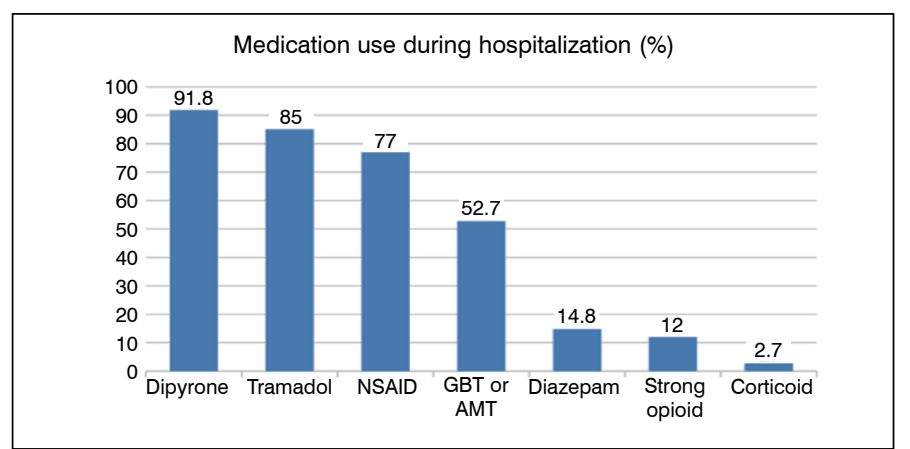

Figure 5. Medication use during hospitalization.

care are due to the excessive and complex use of medication with little scientific evidence, prolonged hospitalization, and the inadvertent use of imaging tests and interventions.

Nunn M.L., ${ }^{13}$ evaluating a sample of 325 patients (from an annual sample of 2,100 patients with acute lumbar pain treated in the emergency room), observed a predominance of female patients (55.1\%), a mean age of 43 years, and a hospitalization rate of $2.5 \%$. The rate of imaging examination use was $27.4 \%$ for spinal radiographs and $4.6 \%$ for tomography. The most commonly used medication in the care unit was ibuprofen (28.3\%), followed by hydromorphone (24.9\%), acetaminophen (21.5\%), and morphine (4.9\%). The admission rates for patients with conditions of intensely strong, moderate, and mild pain were $32.6 \%, 57.6 \%$, and $9.9 \%$, respectively.

Friedman et al., ${ }^{14}$ found similar results, with a mean age of 40 years and a discreet predominance of female patients in the sample (51.2\%). Opioid analgesics were prescribed for $61.7 \%$ of the patients, with most being strong opioids $(71.7 \%)$. The rate of radiography use was $30.5 \%$. Of the total number of patients, $54.2 \%$ presented intense pain and $8 \%$ arrived at the unit via ambulance.

Rizzardo A et al., ${ }^{15}$ evaluating the different presentations of the disease (low back pain, low back pain with radiation, or radiating pain), observed a high rate of imaging examination use (56\%). As regards the risk classification adopted, at admission most of the 
patients (930) were classified as green, 71 classified as yellow, and 227 classified as white, even though the pain scores presented varied between 7.7 and $8.4 / 10$ (intense pain). The rate of morphine use in the emergency room was $47.8 \%$ and the hospitalization rate was $5.3 \%$. The length of stay of hospitalized patients was 15.3 days for lumbar pain without radiation.

Edwards $\mathrm{J}$ et al., ${ }^{16}$ reported the lowest hospitalization rate for low back pain complaints (1.5\%). The author subdivided the group of people who sought emergency care with a low back pain complaint into patients with non-specific low back pain (60.8\%), those with suspected nerve root involvement (6.7\%), and those with lumbar pain associated with a secondary cause (9.9\%). The chances of admission were higher for radiating pain (4.5\%), similar to those observed in the present study.

Kyi $L$ et al., ${ }^{17}$ in their analysis of a group of 712 inpatients with a mean age of 67 years, reported prednisolone, opioid, and neuropathic pain medication use rates of $32 \%, 97 \%$, and $53 \%$, respectively. The same authors were able to verify image examination use rates of $73 \%, 21 \%$, and $15 \%$ for magnetic resonance, simple radiographs, and CT scans, respectively. The mean hospitalization time was 4 days when the treatment was performed in the rheumatology ward and 5 days in the medical clinic. The potency of the opioids used was not reported, but the author found a rate of complications attributable to the medication of $23 \%$.

The Rizzardo, Friedman, and Nunn case series call attention to the high pain scores at the time of admission and to the frequent use of strong opioids to treat acute profiles. The publication by Kyi et al. highlighted a hospitalization time shorter than that of only one other author who analyzed this variable, in addition to high corticosteroid use.

Multiple national guidelines have been published in recent decades, mainly in developed countries. In general, various authors recommend the searching for warning signals, the preferential use of weak analgesics, non-steroidal anti-inflammatories, and muscle relaxers for acute cases, in addition to limiting the use of imaging examinations, corticosteroids, and strong opioids. Early return to the activities of daily living is also recommended for patients with acute low back pain.

Few studies address the topic from the point of view of drug refractoriness when hospitalization is necessary. The studies cited indicate that, under these conditions, a higher quantity of imaging examinations tends to be requested, in addition to the prescription of strong opioids being common.

In recent years, changes to several classic recommendations for the treatment of acute and chronic pain have occurred, such as the contraindication to the use of paracetamol for both conditions, due to the few proven clinical effects, in addition to the contraindication to the use of tricyclic antidepressants (amitriptyline) and antiepileptics (gabapentin, pregabalin) for chronic pain. The same revisions have gone on to recommend the promising use of duloxetine as an adjuvant in the treatment of chronic lumbar pain. 4,5,18-20

In the present study we observed a lower rate of strong opioid use in the emergency room as compared to other similar series and a strong tendency to use tricyclics and antiepileptics during hospitalization. We also observed a high rate of corticosteroid use, despite the absence of recommendations for their use in acute or chronic situations. Such practices are probably due to a common extrapolation of prior recommendations for chronic low back pain, as observed in the work of Kyi $L$ et al. With a lack of specific recommendations for the treatment of refractory acute pain, many physicians end up using medications suggested for the treatment of chronic conditions or other painful syndromes.

We also observed a high rate of spinal tomography use in the emergency room (7.6\%), compared to the other authors mentioned. Such practice is probably due to a sum of factors, such as the medical team's lack of knowledge about the common recommendations in the guidelines, the fear of losing important findings, and the legal consequences of such an occurrence, in addition to the cultural factors linked to a population that often goes to the emergency service spontaneously demanding more expensive complementary examinations. In the city of Serra, direct referrals from other emergency care units for image examinations, analgesia, and hospital care are common, thus overburdening the emergency service while encouraging a culture in the population focused on the overutilization of hospital services.

The main bias of this study is the loss of data due to the inadequate registration of ICDs and the absence of a precise anatomical definition, creating flaws in the calculation of real prevalence. Many patients receive non-specific diagnoses (R52.0 - acute pain and R52.2 - other chronic pain) or present pain in more than one location (neck pain, back pain, and low back pain). In the second situation, the record does not always consider the region where is the most intense, it being possible to record only a single diagnosis in the system. It is possible that, in the future, when analyzing the data prospectively, the prevalence will be even greater than that reported with current information.

\section{CONCLUSIONS}

Low back pain was a highly prevalent symptom in the period studied, with a low percentage of hospitalizations, although higher than that reported in similar studies.

We observed less use of radiographs and strong opioids compared to other authors and an intermediate length of hospitalization in relation to that reported by two of the other authors mentioned, in addition to a higher frequency of evaluation using computed tomography of the spine.

We recommend that future studies be elaborated in order to determine the real socioeconomic impacts of the different manifestations of low back pain in Brazil, using precise anatomical definitions and real quantification of the average pain scores for the multiple presentations of this complaint. In addition, we encourage the dissemination of real clinical practices and the development of prospective studies by other services in order to establish the best therapeutic strategy for acute low back pain in emergency care services. We encourage the adoption of the therapeutic regimen for pain described by the WHO for oncological pain (later adapted by other authors for other types of painful conditions) ${ }^{21}$, especially during hospitalization, considering the potential for major functional impairment associated with situations of more intense pain, associated in selected cases with a psychosocial approach by a multidisciplinary team. We emphasize the importance of paying attention to prevention of the complications associated with the use of strong opioids, especially in the higher risk population (elderly patients or those with a history of illegal drug use).

Also, when we are addressing a frequent condition with great social and economic impact, it is important, as seen in examples of what has already been done in several developed countries, to conduct campaigns at state and federal levels focused on the continuing education of health professionals, especially general practitioners and other primary care professionals. Good results were also obtained with public awareness campaigns focused on preferably directing the care and follow-up of some cases to basic healthcare units. We believe that forming multidisciplinary groups, following the example of those established for the treatment of other chronic diseases such as hypertension and diabetes, distributing pamphlets with simple guidelines, and using applications with diagnostic and therapeutic guidance for the medical field aimed at better preparation of general practitioners to deal with a very common complaint whose prevalence will tend to increase in future years, have great potential.

All authors declare no potential conflict of interest related to this article. 
CONTRIBUTION OF THE AUTHORS: Each author made significant individual contributions to this manuscript. RSR: intellectual concept, data analysis, writing. EBS: data analysis, writing. LGB: review, data analysis. RLF: review. CTVR: intellectual concept, review.

\section{REFERENCES}

1. Edwards J, Hayden J, Asbridge M, Gregoire B, Magee K. Prevalence of low back pain in emergency settings: a systematic review and meta-analysis. BMC Musculoskelet Disord. 2017;18(1):143

2. Traeger AC, Henschke N, Hübscher M, Williams CM, Kamper SJ, Maher CG, et al, Estimating the risk of chronic pain: development and validation of a prognostic model (PICKUP) for patients with acute low back pain. PLoS Med. 2016;13(5):e1002019.

3. Chou $R$, Shekelle P. Will this patient develop persistent disabling low back pain? JAMA 2010;303(13):1295-302

4. Qaseem A, Wilt TJ, McLean RM, Forciea MA. Noninvasive treatments for acute, subacute, and chronic low back pain: a clinical practice guideline from the American College of Physicians. Ann Intern Med. 2017;166(7):514-30.

5. NICE Guideline. Low Back Pain and Sciatica in Over 16s: Assessment and Management. London: National Institute for Health and Care Excellence (UK); 2016.

6. Serrano-Aguilar P, Kovacs FM, Cabrera-Hernández JM, Ramos-Goñi JM, García-Pérez L. Avoidable costs of physical treatments for chronic back, neck and shoulder pain within the Spanish National Health Service: a cross-sectional study. BMC Musculoskelet Disord. 2011:12:287.

7. de Souza FS, Ladeira CS, Costa LOP. Adherence to Back Pain Clinical Practice Guidelines by Brazilian Physical Therapists: A Cross-Sectional Study. Spine (Phila Pa 1976). 2017;42(21):E1251-8

8. Finestone AS, Raveh A, Mirovsky Y, Lahad A, Milgrom C. Orthopaedists' and family practitioners' knowledge of simple low back pain management. Spine (Phila Pa 1976) 2009:34(15):1600-3.

9. Medeiros MMC. Condutas Usuais entre os Reumatologistas Brasileiros: Levantamento Nacional. Rev Bras Reumatol. 2006;46(2):82-92.

10. Buchbinder R, van Tulder M, Oberg B, Costa LM, Woolf A, Schoene M, et al. Low Back pain series working G: low back pain: a call for action. Lancet. 2018:391(10137):2384-8.

11. Foster NE, Anema JR, Cherkin D, Chou R, Cohen SP, Gross DP, et al. Prevention and treatment of low back pain: evidence, challenges, and promising directions. Lancet. 2018;391(10137):2368-83
12. Hartvigsen J, Hancock MJ, Kongsted A, Louw Q, Ferreira ML, Genevay $\mathrm{S}$, et al. What low back pain is and why we need to pay attention. Lancet. 2018;391(10137):2356-67.

13. Nunn ML, Hayden JA, Magee K. Current management practices for patients presenting with low back pain to a large emergency department in Canada. BMC Musculoskelet Disord. 2017;18(1):92.

14. Friedman BW, Chilstrom M, Bijur PE, Gallagher EJ. Diagnostic testing and treatment of low back pain in United States emergency departments: a national perspective.. Spine (Phila Pa 1976). 2010;35(24):1406-11.

15. Rizzardo A, Miceli L, Bednarova R, Guadagnin GM, Sbrojavacca R, Della Rocca G. Low-back pain at the emergency department: still not being managed? Ther Clin Risk Manag. 2016;12:183-7.

16. Edwards J, Hayden J, Asbridge M, Magee K. The prevalence of low back pain in the emergency department: a descriptive study set in the Charles V. Keating Emergency and Trauma Centre, Halifax, Nova Scotia, Canada. BMC Musculosket Disord. $2018 ; 19(1): 306$

17. Kyi L, Kandane-Rathnayake R, Morand E, Roberts LJ. Outcomes of Patients Admitted to Hospital Medical Units with Back Pain. Intern Med J. 2019;49(3):316-22.

18. Skljarevski V, Ossanna M, Liu-Seifert H, Zhang Q, Chappell A, lyengar S, et al. A doubleblind, randomized trial of duloxetine versus placebo in the management of chronic low back pain. Eur J Neurol. 2009;16(9):1041-8.

19. Skljarevski V, Zhang S, Desaiah D, Alaka KJ, Palacios S, Miazgowski T, et al. Duloxetine versus placebo in patients with chronic low back pain: a 12-week, fixed-dose, randomized, double-blind trial. J Pain. 2010;11(12):1282-90.

20. Skljarevski V, Desaiah D, Liu-Seifert H, Zhang Q, Chappell AS, Detke MJ, et al. Efficacy and safety of duloxetine in patients with chronic low back pain. Spine (Phila Pa 1976). 2010;35(13):E578-85

21. Vargas-Schaffer G. Is the WHO analgesic ladder still valid? Twenty-four years of experience. Can Fam Physician. 2010;56(6):514-7. 